\title{
EFISIENSI TEKNIS DAN EKONOMIS USAHATANI UBI KAYU DI KABUPATEN LAMPUNG TENGAH
}

\section{TECHNICAL AND ECONOMIC EFFICIENCY OF CASSAVA IN CENTRAL LAMPUNG REGENCY}

\author{
Fembriarti Erry Prasmatiwi ${ }^{*}{ }^{1}$, Ktut Murniati $^{1}$, Renardi Iswara ${ }^{1}$ \\ Program Studi Magister Agribisnis, Fakultas Pertanian, Universitas Lampung \\ Jl. Soemantri Brojonegoro No 1, Bandar Lampung \\ *E-mail: fembriarti.erry@fp.unila.ac.id \\ (Diterima 29-07-2021; Disetujui 15-12-2021)
}

\begin{abstract}
ABSTRAK
Produktivitas ubikayu yang rendah merupakan salah satu indikasi usahatani tersebut belum efisien. Penelitian bertujuan mengukur pendapatan, efisiensi teknis, faktor penyebab inefisiensi, dan menganalisis efisiensi ekonomis usahatani ubi kayu di Lampung Tengah. Lokasi penelitian dilakukan di sentra ubi kayu yaitu di Kecamatan Terusan Nunyai dan Terbanggi BesarLampung Tengah pada bulan Februari-Maret 2021. Sampel penelitian adalah petani ubi kayu dengan jumlah 84 orang. Fungsi Produksi dan biaya stochastic frontier digunakan untuk menganalisis efisiensi teknis dan ekonomis usahatani ubi kayu. Hasil penelitian menyatakan usahatani ubi kayu di daerah penelitian menguntungkan. Pendapatan atas biaya tunai sebesar Rp11.620.993,22/ha dengan R/C adalah 2,46 serta pendapatan atas biaya total sebesar Rp6.294.767,65/ha dengan R/C 1,47. Tingkat efisiensi teknis 0,85 dan ekonomis 0,79 atau usahatani dalam kategori cukup efisien. Faktor penyebab inefisiensi teknis adalah pendidikan, umur petani, dan pengalaman usahatani. Petani yang mendapatkan akses kredit dan menjadi anggota kelompok tani akan menurunkan inefisiensi.
\end{abstract}

Kata kunci : Efisiensi, Stochastic Frontier, Ubikayu

\section{ABSTRACT}

Cassava farming in Central Lampung Regency has lower productivity than its potential. Low productivity is one of the essential farming indicators that are not efficient yet. This study investigates the income level of cassava farming, technical efficiency and factors causing inefficiency, also the economic efficiency of cassava farming. This research was conducted in the cassava center, the Terbanggi Besar District and the Terusan Nunyai District, Central Lampung. Data were collected from February - March 2021 from 84 respondents of cassava farmers. The efficiency level was analyzed using stochastic frontier Cobb-Douglas. The results obtained that cassava farming in Central Lampung Regency is profitable with cassava farming income at cash costs Rp11,620,993.22/ha and R/C is 2.46; also, income on total costs Rp6,294,761.65/ha with R/C is 1.47. While cassava farming in the study area is both technically (0.85) and economically (0.79) efficient, factors that affect technical efficiency are farmer age, education, and farming experience. It was found that farmer group members and who have access to credit will reduce inefficiency

Keywords: Cassava, Efficiency, Stochastic Frontier

\section{PENDAHULUAN}

Di Indonesia komoditas ubi kayu merupakan bahan pangan penting yang dapat menopang ketahanan pangan masyarakat dan dapat menjadi sumber pangan selain beras. Komoditas ubi kayu juga menjadi input atau bahan baku 
industri dan sumber pakan ternak seperti kambing dan sapi.

Ubi kayu termasuk tanaman umbiumbian. Usahatani ubikayu merupakan salah satu sumber pendapatan utama rumah tangga petani dan mempunyai karakteristik yang khas yang menarik petani untuk menanamnya. Aboki et al. (2013) menyatakan ubikayu mempunyai kandungan karbohidrat. yang berlimpah, berguna sebagai bahan baku industri, dapat tersedia sepanjang tahun, dan dibandingkan dengan tanaman lain ubikayu memiliki tingkat adaptasi lebih tinggi terhadap tanah dengan kesuburan rendah, serta tahan terhadap penyakit, hama, dan kekeringan.

Ubi kayu ditanam hampir seluruh provinsi dan Lampung merupakan produsen nomor satu ubi kayu di Indonesia. Menurut data Kementerian Pertanian (2019), Provinsi Lampung menjadi sentra utama ubi kayu dengan luas panen 256 ribu hektar dan produksi pada tahun 2017 adalah 5,45 juta ton umbi basah serta memberikan share produksi sebesar $28,70 \%$ dari total produksi di Indonesia.

Sentra ubi kayu di Lampung adalah Lampung Tengah. Di kabupaten ini pada tahun 2019 produksi ubi kayu 1.844.663 ton dan produktivitasnya adalah 25 ton/ha
(Dinas Ketahanan Pangan dan Hortikultura Provinsi Lampung, 2019). Penelitian Radjit dan Prasetiaswati (2011), Nugraha et al. (2015), dan Anggraini et al. (2016) melaporkan produktivitas ubi kayu dapat mencapai di atas 30-60 ton/ha. Dengan demikian produktivitas ubi kayu di daerah ini masih dapat ditingkatkan untuk mencapai potensialnya dan peningkatan pendapatan petani.

Produktivitas usahatani ubi kayu yang rendah berhubungan erat dengan permasalahan efisiensi dalam penggunaan faktor produksi. Bifarin et al. (2008) menyatakan efisiensi merupakan faktor penentu peningkatan produktivitas utamanya pada bidang pertanian di wilayah yang memiliki sumberdaya terbatas dan rendahnya tingkat adopsi teknologi oleh petani. Untuk mencapai efisiensi menurut Evaline (2013) dapat dilakukan dengan jalan meminimumkan sumber daya yang digunakan untuk mencapai produksi tertentu atau dengan menggunakan faktor produksi tertentu untuk memaksimumkan produksi. Kemampuan untuk mengalokasikan sumber daya yang optimal ini disebut dengan efisiensi teknis. Apabila efisiensi teknis tercapai, maka petani dapat 
meningkatkan produktivitasnya sehingga dapat meningkatkan pendapatannya.

Peningkatan produktivitas dengan jalan peningkatan efisiensi teknis selain dipengaruhi oleh alokasi penggunaan faktor produksi, juga dipengaruhi oleh kemampuan manajerial dari petani dan faktor sosial ekonominya. Pencapaian efisiensi teknis usahatani merupakan titik awal petani untuk mencapai efisiensi ekonomi dan peningkatan pendapatan petani.

Penelitian bertujuan mengukur tingkat pendapatan, efisiensi teknis dan faktor penyebab inefisiensi teknis, serta menganalisis efisiensi ekonomis usahatani ubi kayu di Kabupaten Lampung Tengah.

\section{METODE PENELITIAN}

Kabupaten Lampung Tengah dipilih secara sengaja sebagai lokasi penelitian karena memiliki produksi tertinggi ubi kayu di Provinsi Lampung. Dari Kabupaten tersebut dipilih dua kecamatan sentra ubi kayu dan terpilih Kecamatan Terbanggi Besar dan Kecamatan Terusan Nunyai. Setiap kecamatan diambil 2 desa untuk dilakukan pengambilan sampel. Untuk Kecamatan Terbanggi Besar, sampel diambil di Desa Adi Jaya dan Desa
Nambah Dadi, sedangkan sampel dari Kecamatan Terusan Nunyai adalah Desa Bandar Agung dan Desa Bandar Sakti.

Responden penelitian adalah petani ubi kayu berjumlah 84 orang. Teknik pengambilan sampel menggunakan Probability Sampling yang artinya setiap petani ubi kayu mempunyai probabilitas atau kesempatan sama untuk diwawancarai sebagai sampel. Pengumpulan data penelitian dilaksanakan pada bulan Februari - Maret 2021.

Pendapatan usahatani diukur menggunakan rumus sebagai berikut:

$$
\begin{gathered}
\pi=T P-T B \\
\pi=(H q \cdot Q)-\sum H x_{i} \cdot X_{i}-B T
\end{gathered}
$$

Keterangan :

$\Pi=$ Pendapatan ubi kayu (Rp)

$\mathrm{TP}=$ Penerimaan total ubi kayu $(\mathrm{Rp})$

$\mathrm{TB}=$ Biaya total $(\mathrm{Rp})$

$\mathrm{Q}=$ Produksi ubi kayu $(\mathrm{kg})$

$\mathrm{Hq}=$ Harga output ubi kayu $(\mathrm{Rp} / \mathrm{kg})$

$\mathrm{X}=$ Jumlah input

$\mathrm{Hx}=$ Harga input (Rp/satuan)

$\mathrm{BT}=$ Biaya tetap $(\mathrm{Rp})$

Pengukuran tingkat efisiensi usahatani ubi kayu menggunakan fungsi produksi dan biaya stochastic frontier serta dianalisis menggunakan software Frontier Version 4.1. Program tersebut dapat menghitung efisiensi dengan 
pendekatan maximum likelihood estimates (MLE). Pendekatan MLE dilakukan dengan fungsi produksi dan biaya stokastik frontier serta dapat mengestimasi tingkat efisiensi yang dicapai baik secara individu maupun ratarata serta sekaligus dapat mengestimasi faktor penyebab inefisiensi (Darmawan, 2016).

Fungsi tersebut merupakan pengembangan fungsi deterministik dan dapat menghitung sekaligus efek tidak dapat diduga pada fungsi produksi frontier. Penggunaan fungsi stochastic frontier diberi tambahan random error vi pada variabel acak nonnegatif (variabel non-negatif random)ui (Coelli et al., 1998).

Model fungsi produksi stochastic frontier yang digunakan sebagai berikut.

$$
\begin{aligned}
\operatorname{Ln} Q= & \alpha_{0}+\alpha_{1} \ln \mathrm{X}_{1}+\alpha_{2} \ln \mathrm{X}_{2}+\alpha_{3} \ln \mathrm{X}_{3} \\
& +\alpha_{4} \ln \mathrm{X}_{4}+\alpha_{5} \ln \mathrm{X}_{5}+\alpha_{6} \ln \mathrm{X}_{6}+ \\
& \alpha_{7} \ln \mathrm{X}_{7}+\alpha_{8} \ln \mathrm{X}_{8}+\mathrm{v}_{\mathrm{i}-}-\mu_{\mathrm{i}}
\end{aligned}
$$

Keterangan:

$\mathrm{Q}=$ Output atau produksi $(\mathrm{kg})$

$\mathrm{X}_{1}=$ Luas lahan ubi kayu (ha)

$\mathrm{X}_{2}=$ jumlah bibit/Batang ubi kayu

$\mathrm{X}_{3}=\mathrm{Ppk} \mathrm{KCl}(\mathrm{kg})$

$\mathrm{X}_{4}=$ Ppk SP-36 $(\mathrm{kg})$

$\mathrm{X}_{5}=$ Ppk Urea $(\mathrm{kg})$

$\mathrm{X}_{6}=\mathrm{P}$ Kandang $(\mathrm{kg})$

$\mathrm{X}_{7}=$ Tenaga Kerja (HKP)

$\mathrm{X}_{8}=\operatorname{Herbisida}(\mathrm{gba})$ $\beta_{0} \quad=$ konstanta/Intersep

$\beta_{\mathrm{i}} \quad=$ Koefisien regresi/penduga

$\mathrm{v}_{\mathrm{i}}-\mu_{\mathrm{i}}=$ Error term ( $\mu \mathrm{i}$ merupakan penyebab inefisiensi teknis serta vi merupakan noise effect,).

Harapan tanda nilai koefisien $\alpha_{01}$, $\alpha_{0}, \alpha_{1}, \alpha_{2}, \alpha_{3}, \ldots, \alpha_{8}>0$. Menurut Coelli et al. (1998), pengukuran efisiensi teknis dengan cara:

$$
\mathrm{TE}_{\mathrm{i}}=\exp \left(-\mathrm{E}\left[\mu_{\mathrm{i}} \mid \epsilon_{\mathrm{i}}\right]\right), \mathrm{i}=1,2,3,4 \ldots, \mathrm{n}
$$

$\mathrm{TE}_{\mathrm{i}}$ merupakan tingkat capaian efisiensi teknis petani ubi kayu ke-i. Nilai Efisiensi teknis adalah $0 \leq \mathrm{TE}_{\mathrm{i}} \leq 1$ dan $\exp \left(-\mathrm{E} \quad\left[\mu_{\mathrm{i}} \mid \epsilon_{\mathrm{i}}\right]\right)$ merupakan mean atau besar nilai yang diharapkan dari $\mu_{\mathrm{i}}$ dengan syarat adalah $\epsilon_{\mathrm{i}}$. Analisis efek inefisiensi teknis berdasarkan parameter distribusi $\left(\mu_{\mathrm{i}}\right)$ sebagai berikut:

$$
\begin{aligned}
\mu_{i}= & \beta_{0}+\beta_{1} S_{1}+\beta_{2} S_{2}+\beta_{3} S_{3}+\beta_{4} S_{4}+ \\
& \beta_{1} D_{1}+\beta_{2} D_{2}
\end{aligned}
$$

Keterangan:

$\mu_{\mathrm{i}} \quad=$ Efek inefisiensi teknis

S1 = Usia petani ubi kayu (tahun)

$\mathrm{S}_{2}=$ Tingkat Pendidikan petani (tahun)

$\mathrm{S}_{3}=$ Ukuran rumah tangga (orang)

$\mathrm{S}_{4}=$ Pengalaman usahatani ubi kayu (tahun)

$\mathrm{D}_{1}=$ Dummy variable kondisi keanggotaan Poktan/kelompok $\operatorname{tani}(1=\operatorname{anggota}, 0=$ tidak $)$ 
$\mathrm{D}_{2}=$ Dummy variable kondisi akses terhadap kredit $\quad(1=$ memiliki akses, $0=$ tidak memiliki)

Harapan tanda koefisien $\beta_{0}, \beta_{1}>0$ $\operatorname{dan} \beta_{2}, \beta_{3,} \beta_{4,} \beta_{5}, \beta_{6}<0$.

Pengukuran efisiensi ekonomis menggunakan prinsip meminimumkan biaya produksi. Fungsi ini diperoleh dengan penurunan fungsi biaya dual berbentuk model fungsi produksi CobbDouglas dan harus bersifat homogen. Fungsi biaya stochastic frontier dapat dituliskan secara matematis sebagai berikut.

$\mathrm{C}=\mathrm{f}\left(\mathrm{H}_{1}, \mathrm{H}_{2}, \mathrm{H}_{3} . \mathrm{H}_{4}, \mathrm{H}_{5}, \mathrm{H}_{6}, \mathrm{H}_{7}, \mathrm{H}_{8}\right)$

Keterangan :

$\mathrm{C}=$ Ongkos/biaya Usahatani $(\mathrm{Rp})$

$\mathrm{H}_{1}=$ Sewa Lahan $(\mathrm{Rp} / \mathrm{ha})$

$\mathrm{H}_{2}=$ Harga Bibit ubi kayu (Rp/kg)

$\mathrm{H}_{3}=$ Harga Ppk Urea $(\mathrm{Rp} / \mathrm{kg})$

$\mathrm{H}_{4}=$ Harga Ppk KCl (Rp/kg)

$\mathrm{H}_{5}=$ Harga Ppk SP-36 (Rp/kg)

$\mathrm{H}_{6}=$ Haga Ppk Kandang $(\mathrm{Rp} / \mathrm{kg})$

$\mathrm{H}_{7}=$ Harga Herbisida (Rp/gba)

$\mathrm{H}_{8}=$ Upah buruh/tng kerja (Rp/HKP)

Pendugaan fungsi biaya stochastic frontier pada penelitian ini menggunakan program Frontier versi 4.1.

Fungsi tersebut, akan menghasilkan hasil pendugaan Cost Efficiency (CE) dan Economic Efficiency (EE) adalah nverse dari Cost Efficiency (CE).

$$
\mathrm{EE}=\frac{1}{\mathrm{CE}} .
$$

Keterangan:

$$
\begin{aligned}
& \mathrm{EE}=\text { Efisiensi ekonomis } \\
& \mathrm{CE}=\text { Cost Eficiency }
\end{aligned}
$$

Nilai efisiensi ekonomi adalah EE $0 \leq \mathrm{EA} \leq 1$.

Tingkat efisiensi ekonomi diklasifikasikan menjadi tiga kategori yaitu kategori belum efisien jika nilai EE $<0,70$; cukup efisien jika nilai EE antara $0,70-0,90 ;$ dan sangat efisien jika nilai $\mathrm{EE} \geq 0,90$.

\section{HASIL DAN PEMBAHASAN}

Petani ubi kayu di Lampung Tengah mayoritas berusia produktif yaitu 93\% berusia antara 25-65 tahun. Tingkat pendidikan formal petani paling banyak Tamat Sekolah Dasar (SD) yaitu 36,91\%, diikuti tamat SMP sebesar 27,38\%, dan $26,19 \%$ petani tamat SLTA. Pengalaman petani dalam berusahatani ubi kayu berkisar 2 sampai 56 tahun dengan ratarata 21,13 tahun. Petani berusia muda memiliki pengalaman bersusahatani yang paling rendah. Jumlah tanggungan keluarga petani rata-rata antara 4-5 orang.

Luas lahan rata-rata pengusahaan ubi kayu di Lampung Tengah 1,23 hektar. Sebesar 50\% petani menanam ubikayu dengan luas lahan 0,5-1 hektar, 34,52\% petani menanam $>1$ hektar dan masih ditemukan $15,48 \%$ petani menanam 
ubikayu $<0,5$ hektar. Varietas ubikayu yang ditanam adalah UJ-3 dan UJ-5. Umur panen varietas UJ-5 adalah 10-12 bulan, sedangkan varietas UJ-3 dipanen saat berumur 8-10 bulan. Budidaya dilakukan dengan cara monokultur.

Mayoritas petani menanam ubi kayu pada bulan Januari-Februari dan akan panen pada bulan OktoberNovember. Namun, ditemukan beberapa petani jika menghadapi kebutuhan mendesak akan memanen ubi kayunya pada umur 8 bulan bahkan kurang. Keseluruhan petani menanam ubi kayu di lahan sendiri dan tidak ditemukan responden yang menyewa atau menyakap. Petani menanam bibit ubi kayu dengan jarak tanam yang bervariasi yaitu $80 \mathrm{~cm} \times 80 \mathrm{~cm}, 70 \mathrm{~cm} \times 80 \mathrm{~cm}, 60 \mathrm{~cm}$ x $80 \mathrm{~cm}$, dan $70 \mathrm{~cm} \mathrm{x} 70 \mathrm{~cm}$.

\section{Biaya dan Pendapatan Usahatani Ubi}

\section{Kayu}

Biaya pengusahaan ubi kayu dibagi atas biaya diperhitungkan dan biaya tunai. Biaya tunai usahatani ubi kayu sebesar Rp7.812.276,55/hektar (Tabel 1) dan paling besar digunakan untuk membayar upah tenaga kerja buruh yang mencapai Rp3.360.262,61/ hektar dan diikuti biaya angkut yaitu Rp1.827.719,71/ha. Tenaga kerja buruh yang berasal dari luar keluarga digunakan pada hamper seluruh aktivitas budidaya ubi kayu. Upah buruh/tenaga luar keluarga berkisar Rp60.000Rp70.000/hari. Sejalan pendapat Muizah et al. (2013) yang menyatakan upah tenaga luar share nya paling tinggi $(45,07 \%)$ terhadap total biaya usahatani ubi kayu, namun berbeda dengan Sari et al (2020) menyatakan komponen biaya pupuk memiliki share yang paling tinggi.

Penerimaan petani ubi kayu merupakan nilai penjualan ubi kayu setelah dikurangi dengan rafaksi. Produktivitas ubi kayu di Lampung Tengah adalah 28.348,82 kg/ha. Namun, dalam penjualan ubi kayu, produksi tersebut harus mengalami pemotongan atau rafaksi. Besar rafaksi bervariasi dan ditentukan jumlah kandungan pati ubi kayu serta tingkat kebersihan umbi. Kadar pati yang disyaratkan oleh pabrik untuk varietas Cassesart adalah paling rendah18-20\%. Ubi kayu dengan kandungan pati yang tinggi akan semakin rendah rafaksinya. Rafaksi Varietas UJ-5 lebih rendah dibandingkan dengan UJ-3. Kadar pati yang dimiliki oleh varietas Varietas UJ-5 lebih tinggi dibandingkan dengan Varietas UJ-3.

Rerata rafaksi sebesar 20\%. Dengan produksi yang dihasilkan $28.348,82 \mathrm{~kg} / \mathrm{ha}$ 
dan harga jual Rp860,12/kg, uang yang diterima sebesar Rp19.553.658,54/ha.

Tabel 1. Pendapatan per hektar usahatani ubi kayu di Lampung Tengah

\begin{tabular}{|c|c|c|c|}
\hline Uraian & $\begin{array}{l}\text { Harga } \\
(\mathrm{Rp})\end{array}$ & Jumlah & $\begin{array}{c}\text { Nilai } \\
\text { (Rp/thn) }\end{array}$ \\
\hline \multicolumn{4}{|c|}{ Penerimaan Usahatani } \\
\hline Output/Prod (kg) & 860,12 & $28.348,82$ & $24.442 .073,17$ \\
\hline Rafaksi 20\% & & $5.669,76$ & $4.888 .414,63$ \\
\hline $\begin{array}{l}\text { Produksi setelah } \\
\text { rafaksi }\end{array}$ & 860,12 & $22.679,06$ & $19.553 .658,54$ \\
\hline \multicolumn{4}{|l|}{ Biaya Produksi } \\
\hline \multicolumn{4}{|l|}{ I.Biaya Tunai } \\
\hline Bibit & 58,27 & $16,223.87$ & $945.364,90$ \\
\hline Ppk KCl & $5.234,78$ & 34,04 & $178.191,91$ \\
\hline Ppk SP36 & $3.354,76$ & 56,86 & $190.751,65$ \\
\hline Ppk Urea & $2.181,93$ & 145,33 & $317.099,89$ \\
\hline Ppk NPK & $2.959,72$ & 116,50 & $344.807,38$ \\
\hline Ppk Organik & 581,46 & 838,46 & $487.530,95$ \\
\hline Herbisida & & $1.034,20$ & $201.146,92$ \\
\hline Tng kerja luar & 65.000 & 51,70 & $3.360 .262,61$ \\
\hline Biaya angkut & & & $1.827 .719,71$ \\
\hline Pajak PBB & & & $79.789,39$ \\
\hline Total Biaya Tunai & & & $7 . .932 .665,32$ \\
\hline \multicolumn{4}{|c|}{ II.Biaya Diperhitungkan } \\
\hline Ongkos sewa lal & & & $3.038 .075,88$ \\
\hline Tng Kerja DK & & 4,29 & $266.437,60$ \\
\hline Biaya penyusuta & & & $2.021 .712,09$ \\
\hline Total Biaya Dip & rhitungkan & & $5.326 .225,57$ \\
\hline III. Total Biaya Us & latani & & $13.258 .890,89$ \\
\hline \multicolumn{4}{|c|}{ IV. Pendapatan usahatani } \\
\hline a. Pendapatan a & s B. tunai & & $11.620 .993,22$ \\
\hline b. Pendapatan a & s B. total & & $6.294 .767,65$ \\
\hline c. $R / C$ atas $B . t u$ & & & 2,46 \\
\hline d. $R / C$ atas B. tot & & & 1,47 \\
\hline
\end{tabular}

Biaya tunai usahatani ubi kayu sebesar Rp7.932.665,32/ha dan biaya total Rp13.258.890,89/ha, dengan demikian pendapatan yang diperoleh petani atas biaya tunai Rp11.620.993,22/ha serta besarnya pendapatan usahatani ubi kayu atas biaya total Rp 11.620.993,22/ha. Besarnya RC ratio berdasar pada biaya tunai 2,46 serta $\mathrm{RC}$ ratio berdasar pada biaya total 1,47 yang mengindikasikan usahatani ubi kayu di Lampung Tengah menguntungkan dibudidayakan.

\section{Efisiensi Teknis dan Ekonomi Usahatani Ubi Kayu}

\section{Efisiensi Teknis}

Fungsi produksi Cobb-Douglas stochastic frontier digunakan untuk mengukur efisiensi teknis usahatani ubi kayu pada penelitian ini. Sebagai variabel yang diduga berpengaruh signifikan terhadap produksi ubi kayu adalah luas lahan ubikayu, jumlah bibit/batang, pupuk KCl, SP-36, urea, pupuk kandang, tenaga kerja dan herbisida.

Pada Tabel 2 disajikan hasil pendugaan fungsi produksi stochastic frontier usahatani ubi kayu. Besarnya nilai sigma-squared 0,3835 atau rendah. Nilai yang rendah mengandung arti bahwa error term inefisiensi teknis (ui) terdistribusi normal. Nilai Gamma pada Tabel 2 adalah 0,9410 dengan $\mathrm{t}$ hitung 51,07 dan sangat nyata pada taraf kepercayaan 99\%. Menurut Darmawan (2016), nilai gamma 0,9410 menunjukkan rasio deviasi inefisiensi teknis (ui) dengan deviasi yang 


\section{EFESIENSI TEKNIS DAN EKONOMIS USAHATANI UBI KAYU \\ DI KABUPATEN LAMPUNG TENGAH \\ Fembriarti Erry Prasmatiwi, Ktut Murniati, Renardi Iswara}

kemungkinan karena variabel acak (vi). Besarnya gamma 0,9410 mengandung makna $94,10 \%$ variasi residual dalam model persamaan bersumber dari inefisiensi dalam proses produksi (ui) dan sisanya 5,90\% karena adanya random error dalam pengukuran (vi). Nilai gamma tersebut lebih besar dibandingkan hasil penelitian di Nigeria (Oladeebo et al., 2012; Girei et al,. 2013).

Tabel 2. Hasil analisis fungsi produksi stochastic frontier usahatani ubi kayu

\begin{tabular}{lcr}
\hline Variabel & coefficient & t-rasio \\
\hline Intersep & $9,9324 * *$ & 36,8742 \\
Luas lahan (X1) & $1,0067 * * *$ & 17,7675 \\
Bibit (X2) & $-0,0026$ & $-0,3066$ \\
Ppk KCl (X3) & $-0,0068$ & $-1,5500$ \\
Ppk SP36 (X4) & $-0,0060$ & $-1,5501$ \\
Ppk urea (X5) & $-0,0066$ & $-0,4249$ \\
Ppk Kandang (X6) & $0,0081 * *$ & 2,2080 \\
Tng kerja (X7) & $0,1117 *$ & 1,9143 \\
Herbisida (X8) & 0,0038 & 0,7088 \\
\hline Sigma-squared & $0,3835^{* * *}$ & 3,0549 \\
Gamma ( $\gamma)$ & $0,9410^{* * *}$ & 51,0675 \\
Nilai L-R test & & 20,26 \\
OLS log likelihood F. & $-0,6181$ & \\
MLE log likelihood F. & 9,5142 & \\
\hline Sumber : Data primer, olahan hasil penelitian,2021
\end{tabular}

Pada Tabel 2 dapat dicermati variabel luas lahan ubi kayu, tenaga kerja, serta jumlah pupuk kandang yang digunakan berpengaruh signifikan atau nyata secara tunggal terhadap produksi ubi kayu. Variabel yang mempunyai pengaruh terbesar terhadap produksi ubi kayu adalah variabel lahan yang ditunjukkan oleh nilai koefisien regresi yang paling tinggi. Efisiensi teknis dapat ditingkatkan dengan jalan perluasan lahan atau ekstensifikasi, intensifikasi dengan menambah pupuk kandang, dan tenaga kerja. Namun, peningkatan efisiensi dengan jalan ekstensifikasi di Lampung Tengah sulit dilakukan karena pemilikan lahan pertanian sangat terbatas. Nilai koefisien luas lahan sebesar 1,0067 yang bermakna jika luas lahan ditingkatkan $1 \%$, produksi ubi kayu akan meningkat 1,0067\% dengan faktor lain tetap. Penelitian Fitriana et al. (2019); Anggraini et al. (2016) sejalan hasil penelitian tersebut.

Nilai koefisien fungsi produksi frontier pupuk kandang 0,0081 yang bermakna setiap ditambahkan pupuk kandang $\quad 1 \%$ akan menyebabkan peningkatan produksi ubi kayu $0,0081 \%$. Koefisien tenaga kerja 0,1117 mempunyai makna setiap bertambahnya tenaga kerja dalam usahatani $1 \%$, produksi ubi kayu akan bertambah sebesar 0,1117\%. Dari Tabel 2 dapat dicermati variabel yang tidak berpengaruh signifikan terhadap produksi adalah penggunaan pupuk $\mathrm{KCl}, \mathrm{SP}-36$, urea, bibit, dan herbisida. 
Tabel 3. Tingkat efisiensi teknis yang dicapai petani ubi kayu di Lampung Tengah

\begin{tabular}{lrrl}
\hline \multirow{2}{*}{$\begin{array}{l}\text { Efisiensi } \\
\text { Teknis }\end{array}$} & \multicolumn{2}{c}{ Jumlah petani } & \multirow{2}{*}{ Keterangan } \\
\cline { 2 - 3 } & (orang) & $(\%)$ & \\
\hline$<0,70$ & 7 & 8,33 & Belum efisien \\
$0,70-0,90$ & 49 & 58,33 & Cukup efisien \\
$>0,90$ & 28 & 33,33 & Sangat efisien \\
\hline Jumlah & 84 & 100 & \\
Rata-rata & 0,85 & & \\
Minimum & 0,31 & & \\
Maksimum & 0,96 & & \\
\hline
\end{tabular}

Sumber: Data primer, diolah (2021)

Besarnya efisiensi teknis yang dihasilkan petani ubi kayu berkisar 0,310,96 atau rerata 0,85 (Tabel 3). Di Lampung Tengah masih ditemukan $8,33 \%$ usahatani ubi kayu yang belum efisien, namun 33,33\% usahatani sangat efisien $(\mathrm{ET}>0,90)$. Besar efisiensi usahatani ubi kayu tersebut termasuk kategori cukup efisien. Jika dibandingkan dengan penelitian dari Itam et al (2015) pada petani ubi kayu di Nigeria besaran efisiensi teknisnya adalah 0,89 ; Ademiluyi (2017) sebesar 0,95; namun hasil penelitian ini lebih baik dibanding Anggraini et a.l (2016) di Lampung sebesar 0,69; Soukkhamthat. and Wong (2016) di Laos yaitu rerata 0,72-0,75, Murniati et al (2021) di Lampung yaitu 0,70 .

\section{Analisis Infesiensi Teknis}

Dengan tingkat efisiensi yang dicapai petani di Lampung Tengah sebesar $85 \%$ berarti tingkat efisiensi masih dapat ditingkatkan sebesar 15\% dengan menganalisis faktor penentu yang diduga mempengaruhi inefisiensi teknis. Tabel 4 disajikan hasil analisis faktor penyebab inefisiensi teknis usahatani.

Tabel 4. Analisis faktor penentu efek inefisiensi teknis usahatani ubi kayu di Lampung Tengah

\begin{tabular}{lcr}
\hline Variabel & coefficient & t-rasio \\
\hline Intersep & $9,9324 * *$ & 36,8742 \\
Usia/umur (S1) & $-1,3732 * *$ & $-2,0700$ \\
Pendidikan (S2) & $0,1775 *$ & 1,9049 \\
Jumlah anggota keluarga & $-0,5588$ & $-1,6031$ \\
(S3) & $1,4667 * *$ & 2,2191 \\
Pengalaman usahatani & & \\
(S4) & $-0,7496 * *$ & $-2,2338$ \\
Keikutsertaan poktan & & \\
(D1) & $-1,8568 *$ & $-1,6950$ \\
Akses kredit (D2) & $0,3835 * * *$ & 3,0549 \\
\hline sigma-squared ** & $0,9410 * * *$ & 51,0675 \\
\hline Gamma $(\gamma) * * *$ & &
\end{tabular}

Sumber: Data primer, diolah (2021)

Tabel 4 menyatakan variabel umur petani $\left(\mathrm{S}_{1}\right)$, pendidikan $\left(\mathrm{S}_{2}\right)$, pengalaman usahatani $\left(\mathrm{S}_{4}\right)$, keanggotaan petani ubi kayu dalam poktan/kelompok tani $\left(D_{1}\right)$, dan akses petani terhadap sumber pembiayaan/kredit $\quad\left(D_{2}\right)$ mempunyai pengaruh nyata terhadap penyebab inefisiensi teknis usahatani ubi kayu di Lokasi penelitian. Usia/umur petani berpengaruh negatif terhadap inefisiensi teknis yang bermakna dengan bertambahnya usia petan, akan bertambah inefisien teknisnya. Sebaliknya, semakin muda usia petani semakin sefisien 


\section{EFESIENSI TEKNIS DAN EKONOMIS USAHATANI UBI KAYU \\ DI KABUPATEN LAMPUNG TENGAH \\ Fembriarti Erry Prasmatiwi, Ktut Murniati, Renardi Iswara}

usahataninya. Pendidikan dan pengalaman mempunyai pengaruh nyata positif pada inefisiensi teknis. Petani berpendidikan tinggi dan berpengalaman tinggi biasanya petani tua sehingga kemampuan teknis dan manajerial lebih rendah dibanding petani muda. Hal ini diperkuat hasil analisis bahwa petani tua semakin tidak efisien usahataninya.

Variabel keanggotaan poktan atau kelompok tani bertanda negatif dan mempunyai pengaruh nyata terhadap inefisiensi teknis yang dicapai petani ubi kayu. Petani ubi kayu anggota poktan dapat mencapai lebih tinggi tingkat efisiensi teknisnya dibanding yang tidak menjadi anggota poktan/kelompok tani. Kelompok tani sering mengadakan penyuluhan, sehingga petani yang tergabung dalam poktan/kelompok tani sering menghadiri kegiatan tersebut yang mengakibatkan ketrampilan budidaya menjadi lebih baik dibanding yang tidak menjadi anggota..

Variabel akses kredit berpengaruh nyata terhadap inefisiensi teknis. Petani yang memiliki akses kredit untuk modal usahatani maka akan menurunkan inefisiensi teknis ubi kayu. Petani sering kekurangan modal untuk usahatani ubi kayu. Setelah panen, pendapatan banyak yang hanya untuk mencukupi kebutuhan rumah tangganya. Kondisi tersebut berakibat terganggunya modal usahatani, serta petani kesulitan membeli pupuk, herbisida, atau membayar upah tenaga kerja luar. Petani yang memiliki akses kredit dapat meminjam modal untuk membeli input usahatani. Dengan peningkatan input, menyebabkan produktivitas usahatani ubi kayu meningkat dan akan menyebabkan berkurangnya inefisiensi. Kenyataan tersebut selaras dengan Fadwiwati et al (2014) yang menyatakan pendidikan, akses kredit, dan keanggotaan poktan berpengaruh terhadap inefisiensi teknis, namum penelitian Podesta dan Rachmina (2011) menemukan hanya ada satu variabel yang berpengaruh terhadap inefisiensi teknis yaitu pendidikan nonformal.

Pada Tabel 4 didapatkan jumlah anggota keluarga tidak mempunyai pengaruh nyata terhadap ketidaefisienan atau inefisiensi teknis dan berbeda denga hasil kajian Anggraini et al. (2016) yang menemukan jumlah anggota keluarga memiliki pengaruh negatif.

\section{Analisis Efisiensi Ekonomis.}

Tabel 5 menampilkan hasil analisis fungsi biaya produksi stochastic frontier usahatani ubi kayu. Variabel yang 
mempunyai pengaruh signifikan yaitu biaya sewa lahan, harga bibit, harga harga pupuk kandang, dan herbisida.

Tabel 5. Hasil analisis fungsi biaya stochastic frontier usahatani ubi kayu di Lampung Tengah

\begin{tabular}{llc}
\hline \multicolumn{1}{c}{ Variabel } & coefficient & t-rasio \\
\hline Intersep & 2,6138 & 1,3741 \\
Harga sewa lahan $\left(\mathrm{H}_{1}\right)$ & $0,8523 * * *$ & 35,4314 \\
Harga bibit $\left(\mathrm{H}_{2}\right)$ & $-0,0172 *$ & $-1,8975$ \\
Harga ppk KCl $\left(\mathrm{H}_{5}\right)$ & 0,0024 & 1,3945 \\
Harga ppk SP36 $\left(\mathrm{H}_{4}\right)$ & 0,0031 & 1,3945 \\
Harga ppk urea $\left(\mathrm{H}_{3}\right)$ & $-0,0011$ & $-0,1107$ \\
Harga ppk kandang $\left(\mathrm{H}_{6}\right)$ & $0,0117 * * *$ & 4,1740 \\
Harga herbisida $\left(\mathrm{H}_{7}\right)$ & $0,5780 * *$ & 2,1825 \\
Upah tenaga kerja $\left(\mathrm{H}_{8}\right)$ & 0,7114 & 0,4370 \\
\hline sigma-squared & 0,0789 & 4,1717 \\
Gamma $(\gamma)$ & 0,9218 & 13,1916 \\
OLS log likelihood F. & 26,2194 & \\
MLE log likelihood F. & 28,7061 & \\
\hline Sumber : Data primer, diolah $(2021)$ &
\end{tabular}

Sewa lahan mempunyai pengaruh paling besar terhadap biaya usahatani ubi kayu. Hal ini sejalan dengan Tabel 2 bahwa luas lahan mempunyai pengaruh paling besar terhadap produksi ubi kayu. Koefisien sewa lahan 0,8523 yang bermakna bahwa jika biaya lahan naik $1 \%$ akan mengakibatkan biaya usahatani bertambah $0,8523 \%$.

Harga pupuk kandang dan herbisida juga berpengaruh positif. Hal ini bermakna jika harga pupuk kandang dan herbisida naik maka biaya produksi usahatani juga naik. Faktor yang tidak mempunyai pengaruh signifikan pada biaya produksi ubi kayu adalah harga
SP36, harga pupuk urea, harga pupuk $\mathrm{KCl}$ dan ongkos tenaga kerja.

Tingkat efisiensi ekonomi yang dicapai petani ubi kayu di Lampung Tengah bervariasi, paling rendah 0,31 dan maksimum 0,96 dengan rata-rata adalah 0,79 atau secara rata-rata tergolong cukup efisien. Dilihat sebarannya, tingkat efisiensi ekonomis usahatani ubi kayu di Lampung Tengah sebesar $61,90 \%$ petani termasuk kedalam kategori cukup, 9,52\% cukup efisien, dan sebesar $21,43 \%$ mencapai sangat efisien secara ekonomis (Tabel 6.) Hasil yang berbeda dari penelitian Anggraini (2016) menyatakan bahwa usahatani ubikayu belum efisien secara ekonomi yaitu 0,47

\begin{tabular}{|c|c|c|c|}
\hline Tabel 6. & $\begin{array}{l}\text { Tingkat e } \\
\text { dicapai } \\
\text { Lampung }\end{array}$ & $\begin{array}{l}\text { siensi } \\
\text { etani } \\
\text { engah } \\
\end{array}$ & $\begin{array}{l}\text { konomis yang } \\
\text { bi kayu di }\end{array}$ \\
\hline \multirow[b]{2}{*}{$\begin{array}{l}\text { Efisiensi } \\
\text { Ekonomis }\end{array}$} & \multicolumn{2}{|c|}{ Ubi kayu } & \multirow[b]{2}{*}{ Keterangan } \\
\hline & $\begin{array}{l}\text { Jumlah } \\
\text { (orang) }\end{array}$ & $(\%)$ & \\
\hline$<0,70$ & 8 & 9,52 & Belum efisien \\
\hline $0,70-0,90$ & 58 & 69,05 & Cukup efisien \\
\hline$>0,90$ & 18 & 21,43 & Sangat efisien \\
\hline Jumlah & 84,00 & 100,00 & \\
\hline Rata-rata & 0,79 & & \\
\hline Minimum & 0,31 & & \\
\hline Maksimum & 0,96 & & \\
\hline
\end{tabular}

\section{KESIMPULAN DAN SARAN}

\section{Kesimpulan}

Di Lampung Tengah budidaya ubi kayu menguntungkan. Produktivitas ubi kayu $28.348,82 \mathrm{~kg}$ namun petani harus menanggung rafaksi sebesar $20 \%$ pada 
saat penjualan umbinya. Pendapatan usahatani ubi kayu atas biaya tunai Rp11.620.993,22/ha dan besarnya RC ratio 2,46 serta pendapatan atas biaya total Rp6.294.767,65/ha dan besarnya RC rasio 1,47 .

Secara teknis pengusahaan ubi kayu di Lampung Tengah cukup efisien dengan rerata yang dicapai adalah 0,85 . Faktor penentu efek inefisiensi teknis yaitu variabel usia/umur petani, pengalaman petani dalam berusahatani, pendidikan, dan akses kredit, dan keanggotaan poktan/kelompok tani. Petani anggota poktan/kelompok tani lebih rendah tingkat inefisiensi terta serta petani yang memiliki akses kredit tingkat efisiensi teknis lebih tinggi dibanding tidak memiliki akses kredit. Ditinjau dari tingkat efisiensi ekonomi, pengusahaan ubi kayu di Lampung Tengah cukup efisien secara ekonomis dengan rerata 0,79 .

\section{Saran}

Produktivitas dan tingkat efisiensi usahatani ubi kayu dapat ditingkatkan dengan memperbaiki manajerial usahatani dan menggunakan input sesuai anjuran. Dalam upaya mengurangi rafaksi atau potongan produksi, petani dapat memperhatikan waktu panen sehingga kadar pati meningkat.

\section{DAFTAR PUSTAKA}

Aboki E, Jongur AAU, Onuand JI, \&Umaru II. (2013). Analysis of technical, economic and allocative efficiencies of cassavaproduction in Taraba State, Nigeria. Journal of Agriculture and Veterinary Science. 5 (3) : 19-26.

Ademiluyi, I.O., Adepoju, S.O. \& OkekeAgulu, K. (2017). Technical efficiency of sustainable cassava farming in Kogi State, Nigeria. Journal of Sustainable Development, 10(1), pp.56-60.

Anggraini, N., Harianto, \& Anggraeni, L. (2016). Efisiensi Teknis, Alokatif Dan Ekonomi Pada Usahatani Ubikayu Di Kabupaten Lampung Tengah, Provinsi Lampung. Jurnal Agribisnis Indonesia. Vol 4 No 1, Juni 2016; halaman 43-56.

Bifarin, J.O., Alimi, T., Baruwa, O.I. \& Ajewole, O.C. (2008). October. Determinant of technical, allocative and economic efficiencies in the plantain (Musa spp.) production industry, Ondo State, Nigeria. In $I V$ International Symposium on Banana: International Conference on Banana and Plantain in Africa: Harnessing International 879. pp. 199-209.

Coelli TJ, Rao DSP, \& Battese GE. (1998). An Introduction to Efficiency and Productivity Analysis. Kluwer Academic Publishers, Boston.

Darmawan, D.P. (2016). Pengukuran Efisiensi Produktif Menggunakan Pendekatan Stochastic

Frontier. Elmatera, Yogyakarta 
Dinas Pertanian Ketahan Pangan dan Hortikultura Provinsi Lampung. (2019). Data Luas Panen, Produksi, dan Produktivitas Ubi Kayu di Provinsi Lampung Tahun 2019. https://dinastph.lampungprov.go.id/ pages/sasaran-produksi. Diakses pada tanggal 18 Juni 2021.

Evaline, Chepng'etich. (2013). Analysis of technical efficiency of smallholder sorghum producers in Machakos and Makindu Districts in Kenya. [Thesis]. Kenya [KE] : Kenyatta University.

Fadwiwati, A.Y., Hartoyo, S., Kuncoro, S.U. \& Rusastra, I.W. (2014). Analisis efisiensi teknis, efisiensi alokatif, dan efisiensi ekonomi usahatani jagung berdasarkan varietas di Provinsi Gorontalo. Jurnal Agro Ekonomi, 32(1), pp.1-12.

Fitirana MD, Zakaria WA, dan Kasymir E. (2019). Analisis efisiensi produksi usahatani ubi kayu di Kecamatan Natar Kabupaten Lampung Selatan. JIIA, 7(1) : 2227

Girei A.A., B. Dire, R.M Yuguda, \& Salihu, M. (2013). Analysis of productivity and technical efficiency of cassava production in Ardo-Kola and Gassol Local Government Areas of Taraba

State, Nigeria. Agriculture, Forestry and Fisheries. 3(1): 1-5.

Itam, K.O., Ajah, E.A., Ofem, U.I. \& Abam, O.E. (2015). Technical efficiency analysis of small scale cassava farmers in Cross River State, Nigeria: A stochastic production frontier approach. Applied Economics and Finance, 2(4), pp.10-18.

[Kementan] Kementerian Pertanian. (2019). Data Lima Tahun Terakhir. https://www.pertanian.go.id/home/? show $=$ page \&act $=$ view\&id $=61$.
Diakses 15 Agustus 2021.

Sari, A.P., Ismono, R.H. \& Adawiyah, R. (2020). Analisis Pendapatan, Persepsi, dan Minat Petani Dalam Berusahatani Ubi Kayu Di Kecamatan Sukadana Kabupaten Lampung Timur. Jurnal Ilmu Ilmu Agribisnis. 8(3), pp.474-481.

Muizah, R., Supardi, S. \& Awami, S.N. (2013). Analisis pendapatan usahatani ubi kayu (Manihot esculenta crantz)(studi kasus Desa Mojo Kecamatan Cluwak Kabupaten Pati). Mediagro Jurnal Ilmu-ilmu Pertanian, 9(2):55-67

Murniati, K., Zakaria, W.A., Endaryanto, T. \& Indah, L.S.M. (2021) Analysis of production efficiency and income to support sustainability of cassava farming in Lampung Tengah District, Lampung Province. In IOP Conference Series: Earth and Environmental Science (Vol. 739, No. 1, p. 012048). IOP Publishing.

Nugraha, H.D., Suryanto, A. and Nugroho, A., 2015. Kajian potensi produktivitas ubikayu (Manihot esculenta Crant.) di Kabupaten Pati. Jurnal Produksi Tanaman, 3(8):673-682.

Oladeebo, J.O \& Oluwaranti, A.S. (2012). Profit Efficiency Among Cassava Producers: Empirical Evidence From South Western Nigeria.Journal of Agricultural Economics And Development. $1(2): 46-52$.

Podesta, R. \& Rachmina, D. (2011) January. Efisiensi teknis dan ekonomis usahatani padi pandan wangi (Kasus di Kecamatan Warung Kondang, Kabupaten Cianjur). In Forum Agribisnis: Agribusiness Forum (Vol. 1, No. 1, pp. 58-75). 
Radjit, B.S. \& Prasetiaswati, N. (2011). Optimasi hasil ubi kayu menggunakan teknologi adaptif. Buletin Iptek Tanaman Pangan 6(2):243-256.

Soukkhamthat, T. and Wong, G.Y., (2016). Technical Efficiency
Analysis of Small-Scale Cassava Farming in Lao PDR. Asian Journal of Agriculture and Development, 13(1362-2017-801), pp.21-40. 